\title{
The role of oil prices in Philips curve modelling and forecasting of inflation
}

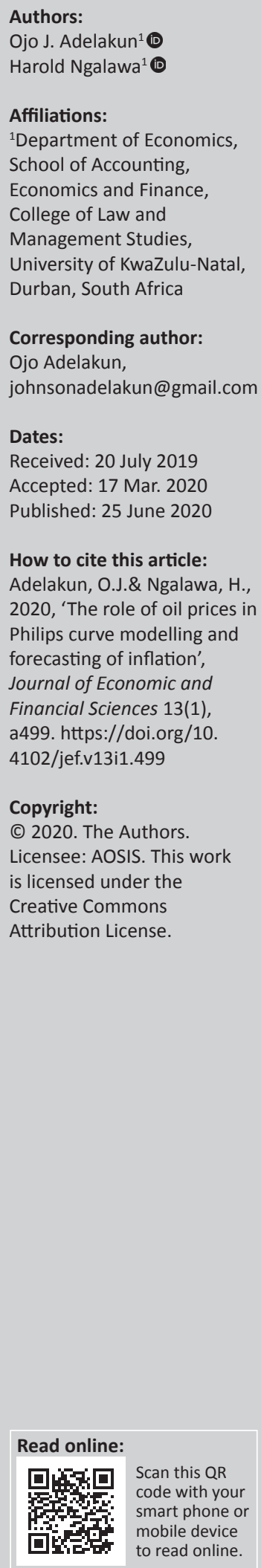

Orientation: The availability of an accurate and a reliable quantitative method for forecasting the behaviour of inflation is of importance, given the emphasis on price stability by central banks.

Research purpose: The conventional Phillips curve predictive model to explain the role of oil prices and associated implications in the forecasting of inflation using data from oil-exporting and oil-importing countries.

Motivation for the study: To determine whether augmenting the traditional demand-side Phillips curve with oil price supply-side shocks matters for the accuracy of predicting inflation using the Phillips curve. Study to investigate the role of oil prices in the Phillip curve accuracy to predict inflation from the perspective of oil exporting -oil importing dichotomy.

Research approach/design and method: We extend the conventional Phillips curve predictive model to explain the role of oil prices and associated implications in the forecasting of inflation using data from oil-exporting and oil-importing countries. The study demonstrates that the forecast performance of the traditional (demand-based) Phillips curve improves when it is augmented with oil prices.

Main findings: We also find that, contrary to previous findings in the literature, the augmented Phillips curve model, which incorporates oil prices as a supply-side factor, outperforms the random walk model.

Practical/managerial implications: The robustness of these findings is evident across different sub-sample periods, forecast horizons and individual oil-exporting and oil-importing countries under consideration.

Contribution/value-add: The comparison outcome further reaffirms that the augmented Phillips curve with changes in oil prices as a proxy for the supply-side factor is the preferred predictive model in both in-sample and out-of-sample forecast performance.

Keywords: inflation-forecasts; predictive model; Phillips curve; oil prices; RMSE; ARMSE; ARDL.

\section{Introduction}

The primary objective of monetary policy in nearly all countries is to achieve price stability. However, the attainment of low and stable inflation has been challenging partially because of the lack of an accurate and reliable method to predict inflation. Not only does the absence of a reliable insight on the evolution of future inflation hinder the attainment of price stability, but it also makes it difficult to formulate sound monetary policy in the absence of accurate inflation forecasts. It is in this light that the quest for an accurate and reliable method for forecasting inflation has continued to constitute a major concern for policymakers, investors and academics. Although the literature is replete with a variety of inflation predictors, the lack of consensus as to what models are best for forecasting inflation makes the task of inflation forecasting challenging. For instance, in spite of the prominence of the Phillips curve as the workhorse of many macroeconomic models in forecasting inflation, the recent empirical history appears to have been characterised by apparent inconsistency concerning the accuracy of the Phillips curve in the predictability of inflation (see Salisu \& Isah 2018).

The Phillips curve approach to forecasting inflation presumes that the economy is closed and hence relies on demand-side or domestic cyclical factors such as output gap or unemployment as the sole determinants of inflation. However, there has been an ongoing debate on the concept of 'global inflation' positing that inflation is becoming more responsive to external forces and less responsive to domestic economic conditions. In economies where inflation is mostly driven by 
external factors, the conventional Phillips curve-based predictive model tends to produce less accurate inflation forecasts. It is, therefore, important to understand the extent to which these external factors matter in the modelling and forecasting of inflation. It is against this background that this study hypothesises that augmenting the conventional Phillips model with these external factors is highly likely to improve the accuracy of inflation forecasting.

Historical data show that positive supply-side global shocks, such as changes in international oil prices, tend to change directly in the same direction with high and persistent inflation, particularly when the oil market is turbulent. Over the years, the international crude oil market has witnessed a series of supply and demand shocks in oil-exporting and oilimporting economies, respectively, attributable to political and economic tensions (Narayan, Liu \& Westerlund 2015; Salisu \& Fasanya 2013). Such episodes of upward and downward swings in the movement of oil prices seem to have reignited a keen interest amongst researchers as well as policymakers on the role of external factors such as supplyside oil price shocks in the predictability of inflation. A rise in oil prices is highly likely to cause an increase in production costs, which may subsequently be manifested in high prices of final goods and services.

Given the foregoing discussion, it is rational to presume that restricting inflation forecasting to domestic economic conditions may lead to inaccuracies, especially for economies that are vulnerable to supply-side shocks such as unanticipated changes in global oil prices. Motivated by the increasing evidence of a correlation between changes in global oil prices and domestic prices as pointed out by Coibion and Gorodnichencko (2015) and Salisu et al. (2017), amongst others, the contribution of this study to the literature is twofold. Firstly, unlike Salisu and Isah (2018) as well as Salisu, Ademuyiwa and Isah (2018) whose studies mainly focussed on the United States and the Organisation for Economic Co-operation and Development (OECD), respectively, the significance of oil prices in the predictability of inflation may yet depend on the oil-exporting or oil-importing peculiarity of an economy. This, therefore, is the motivation for our choice oil export-import dichotomy as the case study.

Secondly, the study explores variant measures of inflation, different forecast performance measures and multiple sample periods to robustly determine the extent to which augmenting the Phillips curve with supply-side oil price shocks is the more accurate approach to predicting inflation. We evaluate and compare the accuracy of inflation forecasts based on demand-side, domestic-based factors and make comparisons with supply-side, external-based factors before testing whether combining the two sides in the same framework enhances the Phillips curve predictability of inflation. The rest of the article is organised into six sections. The Literature section review briefly reviews and discusses the relevant literature while the Theoretical framework section presents the model. The section on Data and preliminary analysis discusses the data and presents some preliminary results while the section on Estimation technique and procedures presents the estimation technique and procedures. The Empirical results and analysis section presents and discusses the findings of the study, and the Conclusion and recommendation section concludes the article.

\section{Literature review}

Amongst the early studies on the inconsistency of the Phillips curve predictive model relative to the auto-regression (AR) process to forecasting inflation are those by Gordon (1982), Stockton and Glassman (1987), Jaditz and Sayers (1994) and Cecchetti (1995). In a subsequent development, Stock and Watson (1999) also evaluated the accuracy and consistency of the Phillips curve approach to forecasting inflation across multiple sub-sample periods. Their finding suggests that Phillips curves based on the unemployment rate might be useful to forecasting inflation but insufficient when compared to forecasting based on other models. A reasonable number of empirical studies on the Phillips curve predictability of inflation seem to have produced results that suggest that the Phillips curve-based predictive model offers few or no advantages in the prediction of inflation relative to the conventional AR approach to forecasting inflation (see, e.g., Ang, Bekaert \& Wei 2007; Atkeson \& Ohanian 2001; Brayton, Roberts \& Williams 1999; Orphanides \& Van Norden 2004).

Notwithstanding that the problem with Phillips curve models may be the simplicity in their specification, studies further extend these models to include activity predictors to ascertain the dominance of the random walk approach to predicting inflation (Ang, Bekaert \& Wei 2007; Canova 2007; Stock \& Watson 2003, 2007). On the extent to which these findings hold for other economies besides the United States, Matheson (2006) studied Australia and New-Zealand and affirmed that the Phillips curve model is relatively less accurate to forecasting inflation when compared to the conventional naive predictive model (random walk hypothesis). It is based on the growing evidence of the relatively less accurate Phillips curves approach in predicting inflation that Stock and Watson (2008) queried the usefulness of activity-based inflation forecasting relative to the AR approach to forecasting inflation. Similar conclusions are reached by Diron and Mojon (2008) and Banbura and Mirza (2013).

Deducible from our review of the extant studies is widespread evidence of inconsistency in the Phillips curve predictability of inflation, compared to the naïve random walk approach to forecasting inflation. Of interest to the present study, however, is whether augmenting the Phillips curve with economic activity variables is likely to enhance its predictability of future inflation. Dotsey and Stark (2005), for instance, were of the view that including economic activity variables in the Phillips curve specification does not enhance its forecasting power to predict inflation. Stock and Watson (2008, 2009), 
however, found the Philips curve based on activity variables to be more accurate in forecasting inflation, compared to other multivariate approaches.

It is given in the aforementioned findings that the present study relies on the increasing evidence of co-movement between the oil price and inflation to test the hypothesis that augmenting the Phillips curve with supply-side oil price shocks is likely to improve the Phillips curve's predictability of inflation. This study acknowledges the contribution of Salisu et al. (2017) and Salisu et al. (2018) as amongst the few exceptions to have shown that accounting for supply-side oil price shocks matter for enhancing the accuracy of the Phillips curve in forecasting. The extent to which oil prices matter in the Phillips curve predictability of inflation varies for oilexporting and oil-importing nations, and analysis of the ensuing relationships is unique to this study.

\section{Theoretical framework}

The traditional approach to the analysis of inflation dynamics is prominently based on the concept of the conventional Phillips curve as well as its long-run counterpart described by the non-accelerating inflation rate of unemployment (NAIRU). Theoretically, there are several competing frameworks for modelling and forecasting inflation (Ascari 2000). In the New-Keynesian Phillips curve, particularly, the rate of inflation depends on marginal cost and the expected inflation rate for the next period. It is this forward-looking feature coupled with the assertion that policy actions are not backward-looking that have seen the New-Keynesian Phillips curve model growing in prominence in the literature. This notwithstanding, the traditional Phillips curve (i.e. the backward-looking Philips curve) remains the mainstay theoretical framework when modelling or predicting inflation. This may partly be unconnected to the fact that the NewKeynesian Phillips curve is not entirely devoid of challenges. Notable amongst these are the strong persistence properties of inflation time series that have not been adequately explained (Salisu et al. 2018; Salisu \& Isah 2018;). However, the shifts in NAIRU have been suggested as necessary to capture such strong persistence and non-linearity (or structural instability) that has continued to characterise inflation (Stock \& Watson 1996). The fact that this approach has been largely embraced in the formulation of inflation forecasting models (Salisu et al. 2018; Salisu \& Isah 2018), amongst others, further gives credence to our preference for the backward-looking Phillips curve as the appropriate theoretical framework in the context of this study.

\section{Model specification}

\section{Single-factor demand-side-based Phillips curve predictive model}

There are two main variants of the single factor demand-side Phillips curve models: one includes the unemploymentinflation trade-off and the other involves the output-inflation trade-off. The former predicts an inverse relationship between the level of unemployment and inflation rate, whilst the latter hypothesises a positive relationship between output and inflation. In the case of the output-inflation perspective, which is most prominent in the literature, higher inflation is predicted if the actual output exceeds its potential (or if unemployment falls below its natural rate). This relationship is formally presented in Equation 1:

$\pi_{t}=\alpha+\beta(L) \pi_{t}+\gamma(L)(\ln \mathrm{y}-\ln \hat{y})_{t}+\varepsilon_{t} ; \quad \gamma>0$

where $\pi$ denotes the inflation rate, $(L)$ is a polynomial in the lag operator and $(\ln y-\ln \hat{y})$ measures the output gap, which proxies the demand-side domestic condition. Hypothetically, inflation is likely to rise if aggregate demand exceeds the potential capacity of the economy.

\section{Single-factor supply-side-based Phillips curve predictive model}

A major shortcoming of the traditional Philips curve approach to predicting inflation is that it is limited to one way of modelling or forecasting inflation. For instance, in spite of the probable sensitiveness of inflation to supply-side shocks, the Phillips curve in Equation 1 does not take into account such cost-push factors. This, as earlier pointed out, undermines the accuracy of the Phillips curve in forecasting inflation over time. To capture whether supply-side cost-push factors matter for enhancing the accuracy of inflation forecasts, we augment Equation 1 with changes in global oil prices to proxy supply-side inflationary factors. The model is now given by:

$\pi_{t}=\alpha+\beta(L) \pi_{t}+\lambda(L)(o p)_{t}+\varepsilon_{t} ; \quad \lambda>0$

[Eqn 2]

The supply-side predictive model based on cost-push in Equation 2 posits that there is a positive correlation between the cost of inputs in the form of global oil prices and inflation rates, where op denotes changes in oil prices computed as $\log \left(\right.$ oil price $_{t} /$ oil rice $\left._{t-1}\right)$

\section{Augmented Phillips curve predictive model}

One of the core objectives of this article is to investigate whether extending the Phillips curve predictive model to include supply-side oil price shocks matter for enhancing the predictability of inflation in oil-exporting and oil-importing economies. The augmented Phillips curve predictive model in Equation 3 enables the incorporation of both demand-side and supply-side factors for forecasting inflation:

$$
\pi_{t}=\alpha+\beta(L) \pi_{t}+\gamma(L)(\ln y-\ln \hat{y})_{t}+\lambda(L) o p_{t}+\varepsilon_{t}
$$

The essence is to determine the extent to which this model is appropriate in forecasting inflation.

\section{The random walk model}

In line with standard practice in the literature, we compare the forecasting accuracy of our preferred predictive model amongst the various Phillips curve predictive models under consideration to the random walk model given by:

$\pi_{t}=\alpha+\beta \pi_{t-1}+\varepsilon_{t}$

[Eqn 4] 
The consideration of the statistical forecasting model in Equation 4 is mainly informed by the historical evidence of such a naïve predictive model as more accurate to forecasting inflation relative to many activities based on predictive models. More importantly, comparing the forecasting accuracy of the random walk process to that of the Phillips curve model helps to give credence to our hypothesis that augmenting the Phillips curve with supplyside oil price shocks matter for the accurate forecasting of inflation.

\section{Data and preliminary analysis}

We consider two alternative measures of inflation, namely, headline inflation and core inflation. The log of Brent crude oil price is used as a measure for the supply-side component of the predictive model, whilst the output gap is used as a proxy for the demand-side component of the predictive model. The latter is measured as $\left(y_{t}-\hat{y}_{t}\right)$, where $y_{t}$ is measured by the $\log$ of industrial production index, and $\hat{y}_{t}$ is the potential output computed using the Hodrick-Prescott filter. All variables are in monthly frequency from January 2000 to December 2016. Whilst acknowledging that there are more than 15 and up to 20 countries ranked amongst the top oilimporting and oil-exporting countries, respectively (see World Fact Book for details on the rankings), the choice of the selected countries was mainly informed by the availability of data. The data were mainly sourced from the International Monetary Fund's (IMF) International Financial Statistics (IFS) except for crude oil prices, which were obtained from the Energy Information Administration (EIA) database.

Whilst examining the statistical properties of the series, we find the average monthly consumer price index of oilexporting countries as relatively lower, compared to the mean value of consumer prices index in oil-importing nations over the same period (see Table 1). In the case of industrial production index, which proxies for demand-side factor in the Phillips curve specification, quite an interesting result and true to the expectation is the fact that the monthly average industrial price index is relatively higher for the selected oil-importing countries, majority of whose economy is industrialised.

Equally notable in Table 1 is the evidence of relatively higher standard deviation values for the consumer price index in oil-exporting countries, compared to oil-importing economies, which is an indication that inflation in oilimporting countries has been less volatile, compared to the oil-exporting countries. The result is mixed with respect to the industrial production index. However, with a standard deviation value of 33.72 , the global oil price seems the most volatile of all the series under consideration. On the statistical distribution of the series, the kurtosis statistic appears predominantly platykurtic except for Japan where both consumer price index and industrial price index are leptokurtic. For the skewness statistic, the direction of the skewness appears mixed across the series and economies.

\section{Estimation technique and procedures}

All the specified predictive models except for the random walk specification in Equation 4 are estimated using the autoregressive distributed lag (ARDL) technique. The choice of the ARDL over the standard linear regression method hinges on its viability to produce robust results even when there is a concern of mixed orders of integration, for instance, $I(0) \& I(1)$. The ARDL model following Pesaran, Shin and Smith (2001) could be represented as follows:

TABLE 1: Descriptive statistics.

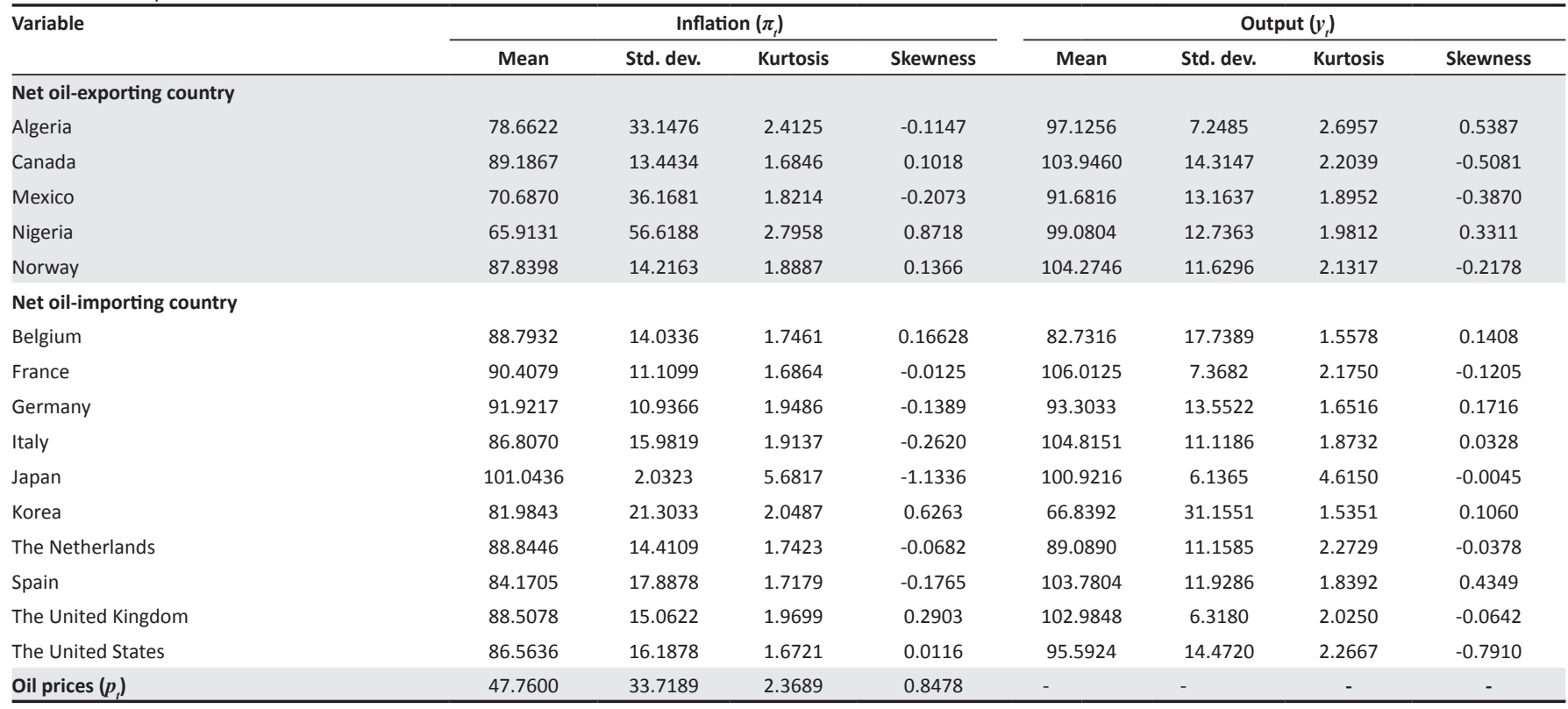

Note: $\pi_{t}$ represents inflation using CPI, Consumer Price Index, $y_{t}$ is output series using IPI, Industrial Production Index, and $p_{t}$ is global oil prices. In addition to the mean values of the series, other statistics considered are standard deviation (std. dev.), Kurtosis and Skewness. 
$\pi_{t}=\alpha+\sum_{i=1}^{p} \delta_{i} \pi_{t-i}+\sum_{j=0}^{q} \gamma_{j} x_{t-j}+\varepsilon_{t}$

where $x_{t}$ denotes domestic demand-side and external supplyside determinants of inflation to be singly analysed in a single factor-based predictive model and subsequently combined in a multiple factors-based predictive model. The lag orders for the dependent and the independent variables are captured with $p$ and $q$, respectively. We follow the Hendry General-toSpecific approach using the Akaike Information Criterion to determine the optimal lag order combination in the ARDL model. The parsimonious model obtained through this process for each of the various variants considered forms the basis for generating parameter estimates and forecasts. Nonetheless, relevant diagnostic and robustness checks are also conducted to verify the reliability of regression estimates.

\section{Forecast performance measure/technique}

Quite a reasonable number of the extant studies have suggested that it is logical to consider multiple sub-sample periods as necessary to ascertain the robustness of a predictive model (Rapach, Strauss \& Zhou 2010; Welch \& Goyal 2008). However, there is no laid down rule to determine such sub-sample periods; instead, analysts often use 25\%, $50 \%$ and/or $75 \%$ of the total observations at their disposal (Narayan \& Gupta 2015; Salisu et al. 2018; Salisu \& Isah 2018). Multiple sub-sample periods in the context of this article would involve using $50 \%$ and $75 \%$ of the total sample. Consequently, there are alternative procedures to follow to produce out-of-sample forecasts; however, the rolling window approach to forecasting still remains the most prominent and, therefore, is most preferred to produce outof-sample forecast in this study.

To determine the forecasting power, the various predictive models are specified: the traditional root mean square error (RMSE) and its adjusted version (ARMSE) developed by Moosa and Burns (2012) are critically examined. These methods of evaluating forecast performance would be computed for the in-sample and out-of-sample forecast. Where the full sample period is given as $t=m+1, \ldots, m+k, m$ will be defined as the in-sample period, whilst $k$ on the other hand denotes forecast horizon such that the RMSE for the two forecast periods is as follows:

$$
\begin{array}{ll}
\text { In-sample: } & \mathrm{RMSE}=\sqrt{\frac{1}{m} \sum_{t=1}^{m}\left(\hat{\pi}_{\mathrm{t}}-\pi_{\mathrm{t}}\right)^{2}} \\
\text { Out-of-sample: } & \mathrm{RMSE}=\sqrt{\frac{1}{k} \sum_{t=1}^{k}\left(\hat{\pi}_{t}-\pi_{t}\right)^{2}}
\end{array}
$$

The adjusted RMSE developed by Moosa and Burns (2012) is calculated using the formula below:

$$
\text { In-sample: } \quad \text { ARMSE }=\sqrt{\frac{C R}{m} \sum_{t=1}^{m}\left(\hat{\pi}_{t}-\pi_{t}\right)^{2}}
$$

Out-of-sample: $\quad$ ARMSE $=\sqrt{\frac{C R}{k} \sum_{t=1}^{k}\left(\hat{\pi}_{t}-\pi_{t}\right)^{2}}$

where $C R$ is the confusion rate computed as $C R=1-D A$, and DA, which is the direction accuracy, is calculated correspondingly to evaluate the in-sample and out-of-sample forecasts as follows:

$$
\begin{aligned}
& \text { In-sample: } \quad \mathrm{DA}=\frac{1}{m} \sum_{t=1}^{m} a_{t} \\
& \text { Out-of-sample: } \quad \mathrm{DA}=\frac{1}{m} \sum_{t=1}^{k} a_{t} \\
& \text { where } a=\left\{\begin{array} { c } 
{ 1 } \\
{ 0 }
\end{array} \text { if } \left\{\begin{array}{l}
\left(\hat{\pi}_{t+1}-\pi_{t}\right)\left(\hat{\pi}_{\mathrm{t}+1}-\pi_{\mathrm{t}}\right)>0 \\
\left(\hat{\pi}_{t+1}-\pi_{t}\right)\left(\hat{\pi}_{\mathrm{t}+1}-\pi_{\mathrm{t}}\right)<0
\end{array}\right.\right.
\end{aligned}
$$

where two competing predictive models have the same RMSE values, the one with the higher $C R$ should have a higher ARMSE (Moosa \& Burns 2012). A good feature of ARMSE as defined in Equations $8 \mathrm{a}$ and $8 \mathrm{~b}$ is that it is not partial to the magnitude of RMSE or direction (CR) (Moosa \& Burns 2012).

\section{Empirical results and analysis Predictability test results}

We commence the presentation of the empirical results with the evaluation of the significance of output ( $y$ ) growth and oil prices as potential predictors of inflation. Presented in Table 2 is the predictability test results for the single factor predictors across both the demand-side and supplyside predictive models. The first section of the table presents the results for the domestic factor demand-side predictive model, whilst the second contains results for the external factor supply-side predictive model. Although, the significance of the coefficients for output and oil prices is evident across the two economies under consideration, it seems relatively more pronounced in the case of the latter. On whether combining the two predictive factors in a single predictive modelling framework matters for enhancing the Phillips curve accuracy to forecast inflation, Table 3 shows the augmented predictive model in this respect as the more accurate, particularly in oil-importing countries.

\section{Forecasting performance evaluation results}

Having determined the predictability status of the predictor series, namely, output $(y)$ and oil prices $(p)$ both in the single- and multiple-factor predictive cases, we then proceed to evaluate the in-sample and out-of-sample forecast performance of the estimated predictive models.

\section{In-sample forecast performance results}

We evaluate and examine the relative in-sample forecast performance of the various activity-based predictive models considered. Essentially, we partitioned the in-sample forecast 


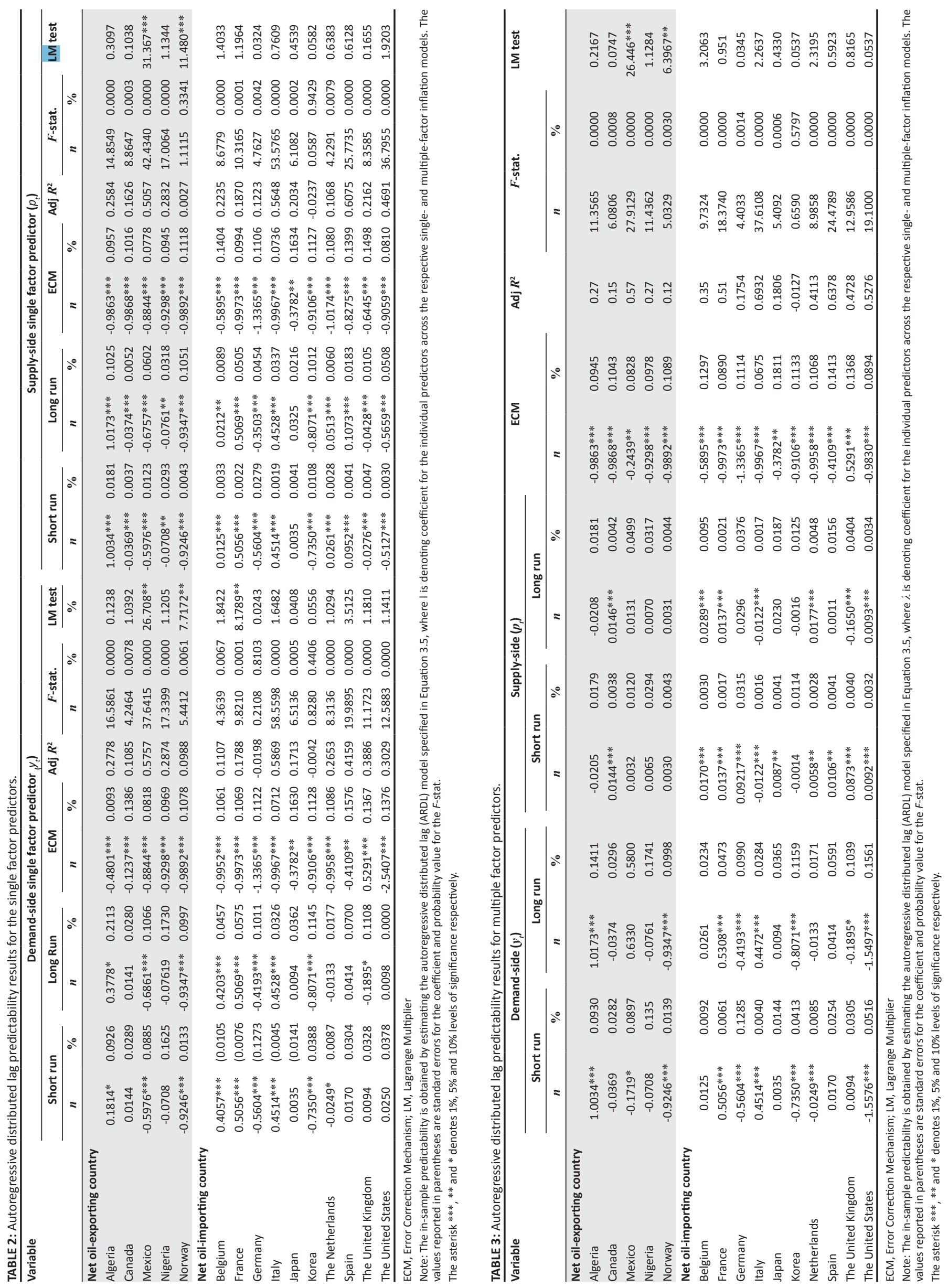


performance analysis into three: firstly, we examine the relative in-sample forecast performance of demand-side single-factorbased predictive model as against supply-side single-factorbased predictive model. Secondly, we compare the forecast performance of each of the single-factor-based predictive models relative to the augmented or multiple-factors-based predictive model. Thirdly, we compare the forecast performance of each of the activity-based predictive model to that of a random walk univariate-based predictive model.

Demand-side versus supply-side in-sample forecast performance: Tables 4 and 5 present the performance of the in-sample forecasts of the different variants of the Phillips curve predictive models estimated. Starting with the singlefactor-based predictive models, the RMSE and ARMSE values in Table 4 show that when $50 \%$ of the total observations are considered, the demand-side predictive model appears to be more accurate in predicting inflation in the case of oilexporting economies. The results are, however, mixed for oilimporting countries even when we extend the sample size to $75 \%$ of the total observation. These results were further subjected to robustness check using an alternative forecast performance measure (ARMSE) and the results were consistent irrespective of the sub-sample period considered.

Multiple-factor versus single-factor in-sample forecast performance: Here, the concern is whether combining both the domestic and external determinants of inflation in the same predictive framework can enhance the predictability of inflation as against the respective demand-side and supplyside predictors in a separate predictive model. The empirical results represented in the middle columns of Tables 4 and 5 for

TABLE 4: In-sample forecast performance using the root mean square error and adjusted root mean square error ( $50 \%$ sample size).

\begin{tabular}{|c|c|c|c|c|c|c|c|c|c|c|}
\hline \multirow[t]{3}{*}{ Variable } & \multicolumn{4}{|c|}{ Single-factor predictive model } & \multirow{2}{*}{\multicolumn{2}{|c|}{$\begin{array}{l}\text { Multiple-factor } \\
\text { predictive model }\end{array}$}} & \multicolumn{4}{|c|}{ Auto-regression predictive model } \\
\hline & \multicolumn{2}{|c|}{ Demand side $\left(y_{t}\right)$} & \multicolumn{2}{|c|}{ Supply side $\left(p_{t}\right)$} & & & \multicolumn{2}{|c|}{$A R(1)$} & \multicolumn{2}{|c|}{$\operatorname{AR}(2)$} \\
\hline & RMSE & ARMSE & RMSE & ARMSE & RMSE & ARMSE & RMSE & ARMSE & RMSE & ARMSE \\
\hline \multicolumn{11}{|c|}{ Net oil-exporting country } \\
\hline Algeria & 0.0331 & 0.0132 & 0.0335 & 0.0146 & 0.0330 & 0.0136 & 0.2371 & 0.2669 & 0.2371 & 1.3912 \\
\hline Canada & 0.0056 & 0.0021 & 0.0055 & 0.0019 & 0.0055 & 0.0019 & 0.0138 & 150806 & 0.0138 & 0.0812 \\
\hline Mexico & 0.0252 & 0.0131 & 0.0276 & 0.0156 & 0.0251 & 0.0133 & 0.0453 & 0.5563 & 0.0453 & 0.2661 \\
\hline Nigeria & 0.0559 & 0.0251 & 0.0549 & 0.0233 & 0.0544 & 0.0231 & 0.0614 & 0.3695 & 0.0614 & 0.3846 \\
\hline Norway & 0.0057 & 0.0017 & 0.0062 & 0.0024 & 0.0052 & 0.0017 & 34.321 & 0.0417 & 34321 & 203.210 \\
\hline \multicolumn{11}{|c|}{ Net oil-importing country } \\
\hline Belgium & 0.0038 & 0.0013 & 0.0038 & 0.0012 & 0.0035 & 0.0009 & 0.0041 & 0.0277 & 0.0042 & 0.0275 \\
\hline France & 0.0028 & 0.0009 & 0.0030 & 0.0010 & 0.0025 & 0.0008 & 0.0030 & 0.0209 & 0.0030 & 0.0194 \\
\hline Germany & 0.0525 & 0.0173 & 0.0412 & 0.0168 & 0.0412 & 0.0168 & 0.2289 & 0.000 & 0.2289 & 1.4229 \\
\hline Italy & 0.0033 & 0.0015 & 0.0037 & 0.0019 & 0.0032 & 0.0015 & 0.0034 & 0.0304 & 0.0034 & 0.0213 \\
\hline Japan & 0.0056 & 0.0018 & 0.0056 & 0.0018 & 0.0056 & 0.0018 & 0.0502 & 0.0441 & 0.0502 & 0.2949 \\
\hline The Netherlands & 0.0030 & 0.0010 & 0.0031 & 0.0011 & 0.0026 & 0.0008 & 0.0036 & 0.0277 & 0.0036 & 0.0226 \\
\hline Spain & 0.0053 & 0.0022 & 0.0046 & 0.0017 & 0.0046 & 0.0018 & 0.0062 & 0.0386 & 0.0062 & 0.0398 \\
\hline The United Kingdom & 0.0054 & 0.0015 & 0.0065 & 0.0022 & 0.0050 & 0.0013 & 258.55 & 0.0771 & 258.55 & 1516.9 \\
\hline The United States & 0.0030 & 0.0012 & 0.0025 & 0.0010 & 0.0025 & 0.0010 & 0.0031 & 0.0224 & 0.0031 & 0.0202 \\
\hline
\end{tabular}

RMSE, root mean square error; ARMSE, adjusted root mean square error; AR, auto-regression.

TABLE 5: In-sample forecast performance using the root mean square error and adjusted root mean square error (75\% sample size).

\begin{tabular}{|c|c|c|c|c|c|c|c|c|c|c|}
\hline \multirow[t]{3}{*}{ Variable } & \multicolumn{4}{|c|}{ Single-factor predictive model } & \multirow{2}{*}{\multicolumn{2}{|c|}{$\begin{array}{l}\text { Multiple-factor } \\
\text { predictive model }\end{array}$}} & \multicolumn{4}{|c|}{ Auto-regression predictive model } \\
\hline & \multicolumn{2}{|c|}{ Demand side $\left(y_{t}\right)$} & \multicolumn{2}{|c|}{ Supply side $\left(p_{t}\right)$} & & & \multicolumn{2}{|c|}{$\mathrm{AR}(1)$} & \multicolumn{2}{|c|}{$\operatorname{AR}(2)$} \\
\hline & RMSE & ARMSE & RMSE & ARMSE & RMSE & ARMSE & RMSE & ARMSE & RMSE & ARMSE \\
\hline \multicolumn{11}{|c|}{ Net oil-exporting country } \\
\hline Algeria & 0.0299 & 0.0126 & 0.0299 & 0.0121 & 0.0295 & 0.0120 & 0.3669 & 0.4508 & 0.3669 & 2.8993 \\
\hline Canada & 0.0060 & 0.0021 & 0.0054 & 0.0017 & 0.0054 & 0.0017 & 0.0098 & 25086 & 0.0098 & 0.0816 \\
\hline Mexico & 0.0242 & 0.0122 & 0.0249 & 0.0133 & 0.0243 & 0.0122 & 0.0526 & 0.7822 & 0.0526 & 0.4239 \\
\hline Nigeria & 0.0508 & 0.0210 & 0.0506 & 0.0205 & 0.0509 & 0.0219 & 0.0543 & 0.4723 & 0.0543 & 0.4685 \\
\hline Norway & 0.0059 & 0.0016 & 0.0062 & 0.0021 & 0.0057 & 0.0018 & 0.0065 & 0.0571 & 0.0065 & 0.0581 \\
\hline \multicolumn{11}{|c|}{ Net oil-importing country } \\
\hline Belgium & 0.0043 & 0.0014 & 0.0040 & 0.0015 & 0.0036 & 0.0012 & 0.0054 & 0.0437 & 0.0054 & 0.0472 \\
\hline France & 0.0032 & 0.0010 & 0.0032 & 0.0011 & 0.0025 & 0.0007 & 0.0037 & 0.0331 & 0.0037 & 0.0335 \\
\hline Germany & 0.0429 & 0.0151 & 0.0395 & 0.0142 & 0.0380 & 0.0153 & 0.2205 & 0.0000 & 0.2205 & 1.8375 \\
\hline Italy & 0.0038 & 0.0017 & 0.0039 & 0.0018 & 0.0037 & 0.0016 & 0.0041 & 0.0590 & 0.0041 & 0.0352 \\
\hline Japan & 0.0053 & 0.0018 & 0.0053 & 0.0020 & 0.0052 & 0.0019 & 0.0107 & 0.0613 & 0.0107 & 0.0885 \\
\hline The Netherlands & 0.0036 & 0.0011 & 0.0040 & 0.0012 & 0.0031 & 0.0009 & 0.0045 & 0.0400 & 0.0045 & 0.0401 \\
\hline Spain & 0.0077 & 0.0027 & 0.0069 & 0.0018 & 0.0066 & 0.0018 & 0.0138 & 0.0776 & 0.0138 & 0.1185 \\
\hline The United Kingdom & 0.0062 & 0.0021 & 0.0064 & 0.0022 & 0.0066 & 0.0025 & 20348 & 0.0923 & 20348 & 16283 \\
\hline The United States & 0.0058 & 0.0023 & 0.0044 & 0.0015 & 0.0040 & 0.0013 & 85605 & 0.0596 & 85605 & 68071 \\
\hline
\end{tabular}

RMSE, root mean square error; ARMSE, adjusted root mean square error; AR, auto-regression. 
$50 \%$ and $75 \%$ sub-samples, respectively, seem to be suggesting that augmenting the Phillips curve predictive with supplyside oil price shocks matters for the predictability of inflation. The finding seems consistent for oil-importing nations. However, the alternative forecast performance measure and varying sample periods are rather episodic for Mexico and Nigeria in the case of oil-exporting economies.

\section{Out-of-sample forecast performance results}

Because the existence of in-sample predictability is not necessarily a sufficient condition to assume out-of-sample predictability, we extend the analysis to out-of-forecast performance evaluation. Exploring a rolling window approach to forecasting inflation, we consider one-quarter period $(h=1)$ and two-quarter periods $(h=2)$ ahead of forecast horizons.
Similar to the in-sample analyses, we consider multiple subsample periods of $50 \%$ and $75 \%$ of the total observations.

Demand-side versus supply-side out-of-sample forecast performance: Starting with the forecast performance results generated using half $(50 \%)$ of the total observations, the empirical results in Table 6 show that when forecasting for the one quarter ahead, the traditional demand-side Phillips curve model is likely to be more accurate to forecast inflation in the net oil-importing economies. For instance, the RMSE values in Table 6 seem relatively lower for the demand-side predictor in a number of the selected countries as against the RMSE for the supply-side predictor. However, whilst there is little or no significant difference in the results even when we extend our forecast horizon to two-quarter periods ahead in Table 7 , the supply-side-based Phillips curve

TABLE 6: Out-of-sample forecast performance using the root mean square error and adjusted root mean square error for $k=1$ ( $50 \%$ sample size).

\begin{tabular}{|c|c|c|c|c|c|c|c|c|c|c|}
\hline \multirow[t]{3}{*}{ Variable } & \multicolumn{4}{|c|}{ Single-factor predictive model } & \multirow{2}{*}{\multicolumn{2}{|c|}{$\begin{array}{l}\text { Multiple-factor } \\
\text { predictive model }\end{array}$}} & \multicolumn{4}{|c|}{ Auto-regression predictive model } \\
\hline & \multicolumn{2}{|c|}{ Demand side $\left(y_{t}\right)$} & \multicolumn{2}{|c|}{ Supply side $\left(p_{t}\right)$} & & & \multicolumn{2}{|c|}{$A R(1)$} & \multicolumn{2}{|c|}{$\operatorname{AR}(2)$} \\
\hline & RMSE & ARMSE & RMSE & ARMSE & RMSE & ARMSE & RMSE & ARMSE & RMSE & ARMSE \\
\hline \multicolumn{11}{|c|}{ Net oil-exporting country } \\
\hline Algeria & 0.0296 & 0.0160 & 0.0276 & 0.0149 & 0.0288 & 0.0156 & 0.0549 & 0.0462 & 0.4187 & 0.3521 \\
\hline Canada & 0.0035 & 0.0012 & 0.0035 & 0.0000 & 0.0035 & 0.0000 & 28871 & 26867 & 0.0125 & 0.0116 \\
\hline Mexico & 0.0198 & 0.0072 & 0.0208 & 0.0076 & 0.0214 & 0.0078 & 0.1133 & 0.1055 & 0.0575 & 0.0535 \\
\hline Nigeria & 0.0352 & 0.0129 & 0.0298 & 0.0109 & 0.0299 & 0.0109 & 0.0506 & 0.0471 & 0.0564 & 0.0525 \\
\hline Norway & 0.0036 & 0.0000 & 0.0040 & 0.0014 & 0.0054 & 0.0000 & 0.0042 & 0.0040 & 242.5743 & 225.7408 \\
\hline \multicolumn{11}{|c|}{ Net oil-importing country } \\
\hline Belgium & 0.0027 & 0.0010 & 0.0023 & 0.0008 & 0.0027 & 0.0010 & 0.0023 & 0.0019 & 0.0022 & 0.0021 \\
\hline France & 0.0020 & 0.0000 & 0.0028 & 0.0010 & 0.0020 & 0.0000 & 0.0027 & 0.0026 & 0.0028 & 0.0026 \\
\hline Germany & 0.0069 & 0.0025 & 0.0103 & 0.0037 & 0.0101 & 0.0037 & 0.0000 & 0.0000 & 0.2293 & 0.2134 \\
\hline Italy & 0.0032 & 0.0012 & 0.0040 & 0.0021 & 0.0042 & 0.0015 & 0.0020 & 0.0017 & 0.0026 & 0.0024 \\
\hline Japan & 0.0025 & 0.0000 & 0.0024 & 0.0000 & 0.0024 & 0.0000 & 0.0045 & 0.0042 & 0.0729 & 0.0679 \\
\hline The Netherlands & 0.0040 & 0.0000 & 0.0044 & 0.0000 & 0.0033 & 0.0000 & 0.0069 & 0.0064 & 0.0056 & 0.0056 \\
\hline Spain & 0.0105 & 0.0000 & 0.0087 & 0.0000 & 0.0086 & 0.0000 & 0.0107 & 0.0107 & 0.0111 & 0.0111 \\
\hline The United Kingdom & 0.0040 & 0.0000 & 0.0068 & 0.0000 & 0.0063 & 0.0023 & 0.0129 & 0.0120 & 1770.7 & 1647.8 \\
\hline The United States & 0.0045 & 0.0016 & 0.0043 & 0.0015 & 0.0043 & 0.0015 & 0.0048 & 0.0045 & 0.0046 & 0.0043 \\
\hline
\end{tabular}

RMSE, root mean square error; ARMSE, adjusted root mean square error; $k, k$ th period ahead; AR, auto-regression.

TABLE 7: Out-of-sample forecast performance using the root mean square error and adjusted root mean square error for $k=2$ ( $50 \%$ sample size).

\begin{tabular}{|c|c|c|c|c|c|c|c|c|c|c|}
\hline \multirow[t]{3}{*}{ Variable } & \multicolumn{4}{|c|}{ Single-factor predictive model } & \multirow{2}{*}{\multicolumn{2}{|c|}{$\begin{array}{l}\text { Multiple-factor predictive } \\
\text { model }\end{array}$}} & \multicolumn{4}{|c|}{ Auto-regression predictive model } \\
\hline & \multicolumn{2}{|c|}{ Demand side $\left(v_{t}\right)$} & \multicolumn{2}{|c|}{ Supply side $\left(p_{t}\right)$} & & & \multicolumn{2}{|c|}{$\operatorname{AR}(1)$} & \multicolumn{2}{|c|}{ AR(2) } \\
\hline & RMSE & ARMSE & RMSE & ARMSE & RMSE & ARMSE & RMSE & ARMSE & RMSE & ARMSE \\
\hline \multicolumn{11}{|c|}{ Net oil-exporting country } \\
\hline Algeria & 0.0034 & 0.0186 & 0.0328 & 0.0204 & 0.0336 & 0.0181 & 0.0593 & 0.0464 & 0.0593 & 0.3411 \\
\hline Canada & 0.0036 & 0.0013 & 0.0033 & 0.0008 & 0.0034 & 0.0008 & 692976.6 & 582721.5 & 692966.6 & 0.0106 \\
\hline Mexico & 0.0235 & 0.0127 & 0.0232 & 0.0125 & 0.0254 & 0.0137 & 0.1160 & 0.0975 & 0.1160 & 0.0505 \\
\hline Norway & 0.0041 & 0.0010 & 0.0044 & 0.0016 & 0.0054 & 0.0013 & 0.0046 & 0.0042 & 0.0046 & 366.3541 \\
\hline \multicolumn{11}{|c|}{ Net oil-importing country } \\
\hline Belgium & 0.0035 & 0.0013 & 0.0032 & 0.0011 & 0.0028 & 0.0010 & 0.0036 & 0.0032 & 0.0036 & 0.0033 \\
\hline France & 0.0024 & 0.0009 & 0.0028 & 0.0010 & 0.0025 & 0.0009 & 0.0028 & 0.0026 & 0.0028 & 0.0026 \\
\hline Germany & 0.0060 & 0.0027 & 0.0169 & 0.0077 & 0.0169 & 0.0077 & 0.0000 & 0.0000 & 0.0000 & 0.1924 \\
\hline Italy & 0.0029 & 0.0010 & 0.0037 & 0.0020 & 0.0040 & 0.0018 & 0.0018 & 0.0016 & 0.0018 & 0.0021 \\
\hline Japan & 0.0035 & 0.0000 & 0.0032 & 0.0000 & 0.0032 & 0.0000 & 0.0063 & 0.0056 & 0.0063 & 0.0674 \\
\hline The Netherlands & 0.0032 & 0.0000 & 0.0036 & 0.0000 & 0.0024 & 0.0000 & 0.0061 & 0.0057 & 0.0061 & 0.0046 \\
\hline Spain & 0.0106 & 0.0000 & 0.0092 & 0.0000 & 0.0092 & 0.0000 & 0.0107 & 0.0107 & 0.0107 & 0.0111 \\
\hline The United Kingdom & 0.0033 & 0.0000 & 0.0059 & 0.0000 & 0.0052 & 0.0013 & 0.0119 & 0.0100 & 0.0119 & 2478.2 \\
\hline The United States & 0.0043 & 0.0011 & 0.0038 & 0.0009 & 0.0038 & 0.0009 & 0.0050 & 0.0045 & 0.0050 & 0.0042 \\
\hline
\end{tabular}

RMSE, root mean square error; ARMSE, adjusted root mean square error; $k, k$ th period ahead; AR, auto-regression. 
model rather than the traditional demand-side appears to be more accurate when the forecast horizon is $h=2$ in the case of oil-exporting countries. Tables 8 and 9 extend our sample size for the out-of-sample forecasting evaluation from $50 \%$ to $75 \%$ of the total observations. However, the finding shows no evidence of a significant difference in the relative out-of-sample forecast performance of the traditional demand-side and the supply-side predictive models. Because of inconsistency with the in-sample forecast performance evaluation, we also subject the out-ofsample forecast results to robustness check using ARMSE. Again, we find the results to be robust and consistent across different sub-sample periods and forecast horizons.

\section{Multiple-factor versus single-factor out-of-sample forecast performance}

Similar to in-sample forecast performance reports, the RMSE forecast performance evaluation results in Tables 5 and 6 show that our proposed augmented (multi-factor)-based predictive model consistently outperforms the respective single-factor-based predictive models. This evidence of a preference for the augmented Phillips curve predictive model seems consistent and robust across different forecast horizons and sub-sample periods. Consequently, we also explore the adjusted version of the RMSE to further ascertain the relative accuracy of the multi-factor predictive model against the single-factor predictive models. The multiple-factor-based

TABLE 8: Out-of-Sample Forecast Performance using the root mean square error and adjusted root mean square error for $k=1$ ( $75 \%$ sample size).

\begin{tabular}{|c|c|c|c|c|c|c|c|c|c|c|}
\hline \multirow[t]{3}{*}{ Variable } & \multicolumn{4}{|c|}{ Single-factor predictive model } & \multirow{2}{*}{\multicolumn{2}{|c|}{$\begin{array}{l}\text { Multiple-factor } \\
\text { predictive model }\end{array}$}} & \multicolumn{4}{|c|}{ Auto-regression predictive model } \\
\hline & \multicolumn{2}{|c|}{ Demand side $\left(y_{t}\right)$} & \multicolumn{2}{|c|}{ Supply side $\left(p_{t}\right)$} & & & \multicolumn{2}{|c|}{$\operatorname{AR}(1)$} & \multicolumn{2}{|c|}{$\operatorname{AR}(2)$} \\
\hline & RMSE & ARMSE & RMSE & ARMSE & RMSE & ARMSE & RMSE & ARMSE & RMSE & ARMSE \\
\hline \multicolumn{11}{|c|}{ Net oil-exporting country } \\
\hline Algeria & 0.0123 & 0.0045 & 0.0099 & 0.0000 & 0.0108 & 0.0039 & 0.0578 & 0.0538 & 0.6454 & 0.6006 \\
\hline Canada & 0.0050 & 0.0018 & 0.0037 & 0.0013 & 0.0038 & 0.0014 & 22327 & 20777 & 0.0076 & 0.0076 \\
\hline Mexico & 0.0167 & 0.0061 & 0.0174 & 0.0063 & 0.0172 & 0.0063 & 0.1118 & 0.1041 & 0.0642 & 0.0597 \\
\hline Norway & 0.0057 & 0.0000 & 0.0059 & 0.0000 & 0.0054 & 0.0000 & 0.0063 & 0.0063 & 0.0062 & 0.0062 \\
\hline \multicolumn{11}{|c|}{ Net oil-importing country } \\
\hline Belgium & 0.0042 & 0.0000 & 0.0036 & 0.0000 & 0.0024 & 0.0000 & 0.0045 & 0.0045 & 0.0040 & 0.0040 \\
\hline France & 0.0031 & 0.0011 & 0.0039 & 0.0014 & 0.0026 & 0.0000 & 0.0043 & 0.0040 & 0.0042 & 0.0039 \\
\hline Germany & 0.0079 & 0.0000 & 0.0085 & 0.0000 & 0.0122 & 0.0000 & 0.0000 & 0.0000 & 0.2211 & 0.2211 \\
\hline Italy & 0.0013 & 0.0000 & 0.0011 & 0.0004 & 0.0014 & 0.0000 & 0.0074 & 0.0062 & 0.0025 & 0.0023 \\
\hline Korea & 0.0018 & 0.0006 & 0.0020 & 0.0007 & 0.0019 & 0.0007 & 0.0414 & 0.0385 & 0.0416 & 0.0387 \\
\hline The Netherlands & 0.0025 & 0.0000 & 0.0052 & 0.0028 & 0.0035 & 0.0000 & 0.0051 & 0.0043 & 0.0054 & 0.0050 \\
\hline Spain & 0.0094 & 0.0000 & 0.0092 & 0.0000 & 0.0096 & 0.0000 & 0.0088 & 0.0088 & 0.0204 & 0.0172 \\
\hline The United Kingdom & 0.0055 & 0.0020 & 0.0058 & 0.0021 & 0.0046 & 0.0016 & 0.0051 & 0.0047 & 19208 & 17875 \\
\hline The United States & 0.0085 & 0.0046 & 0.0052 & 0.0028 & 0.0048 & 0.0017 & 0.0088 & 0.0082 & 85164 & 79254 \\
\hline
\end{tabular}

RMSE, root mean square error; ARMSE, adjusted root mean square error; $k, k$ th period ahead; AR, auto-regression.

TABLE 9: Out-of-sample forecast performance using the root mean square error and adjusted root mean square error for $k=2$ ( $75 \%$ sample size).

\begin{tabular}{|c|c|c|c|c|c|c|c|c|c|c|}
\hline \multirow[t]{3}{*}{ Variable } & \multicolumn{4}{|c|}{ Single-factor predictive model } & \multirow{2}{*}{\multicolumn{2}{|c|}{$\begin{array}{l}\text { Multiple-factor } \\
\text { predictive model }\end{array}$}} & \multicolumn{4}{|c|}{ Auto-regression predictive model } \\
\hline & \multicolumn{2}{|c|}{ Demand side $\left(y_{t}\right)$} & \multicolumn{2}{|c|}{ Supply side $\left(p_{t}\right)$} & & & \multicolumn{2}{|c|}{$\mathrm{AR}(1)$} & \multicolumn{2}{|c|}{$\operatorname{AR}(2)$} \\
\hline & RMSE & ARMSE & RMSE & ARMSE & RMSE & ARMSE & RMSE & ARMSE & RMSE & ARMSE \\
\hline \multicolumn{11}{|c|}{ Net oil-exporting country } \\
\hline Algeria & 0.0118 & 0.0043 & 0.0111 & 0.0028 & 0.0115 & 0.0042 & 0.0539 & 0.0480 & 0.0539 & 0.5842 \\
\hline Canada & 0.0046 & 0.0011 & 0.0039 & 0.0014 & 0.0040 & 0.0014 & 33850 & 31501 & 33850 & 0.0090 \\
\hline Mexico & 0.0184 & 0.0084 & 0.0174 & 0.0080 & 0.0187 & 0.0085 & 0.1111 & 0.0987 & 0.1111 & 0.0564 \\
\hline Norway & 0.0057 & 0.0014 & 0.0065 & 0.0016 & 0.0054 & 0.0000 & 0.0068 & 0.0064 & 0.0068 & 0.0063 \\
\hline \multicolumn{11}{|c|}{ Net oil-importing country } \\
\hline Belgium & 0.0042 & 0.0010 & 0.0036 & 0.0000 & 0.0028 & 0.0007 & 0.0044 & 0.0044 & 0.0044 & 0.0044 \\
\hline France & 0.0028 & 0.0010 & 0.0037 & 0.0013 & 0.0024 & 0.0009 & 0.0039 & 0.0036 & 0.0039 & 0.0036 \\
\hline Germany & 0.0066 & 0.0024 & 0.0087 & 0.0000 & 0.0100 & 0.0036 & 0.0000 & 0.0000 & 0.0000 & 0.2055 \\
\hline Italy & 0.0026 & 0.0009 & 0.0026 & 0.0012 & 0.0022 & 0.0008 & 0.0070 & 0.0059 & 0.0070 & 0.0026 \\
\hline Korea & 0.0068 & 0.0025 & 0.0070 & 0.0025 & 0.0071 & 0.0026 & 0.0431 & 0.0401 & 0.0431 & 0.0403 \\
\hline The Netherlands & 0.0024 & 0.0006 & 0.0045 & 0.0020 & 0.0030 & 0.0007 & 0.0043 & 0.0036 & 0.0043 & 0.0042 \\
\hline Spain & 0.0099 & 0.0000 & 0.0098 & 0.0000 & 0.0102 & 0.0000 & 0.0093 & 0.0093 & 0.0093 & 0.0180 \\
\hline The United Kingdom & 0.0053 & 0.0013 & 0.0053 & 0.0013 & 0.0056 & 0.0020 & 0.0072 & 0.0064 & 0.0072 & 30553 \\
\hline The United States & 0.0067 & 0.0036 & 0.0046 & 0.0024 & 0.0043 & 0.0019 & 0.0068 & 0.0060 & 0.0068 & 14052 \\
\hline
\end{tabular}

RMSE, root mean square error; ARMSE, adjusted root mean square error,; $k, k$ th period ahead; AR, auto-regression. 
predictive model still appears to be the most accurate for forecasting inflation. This is in line with results from previous studies that compare the forecast performance of different single-factor variants of Phillips curve to those that examine the role of commodity prices in inflation forecasting (see Cecchetti et al. 2000; Chen et al. 2014; Salisu et al. 2018).

\section{Additional results and robustness tests}

To determine the robustness of our results, we compare our best-performing activity-based predictive model, for instance, the augmented Phillips curve model with the random walk approach to forecasting inflation. The comparison reveals that our preferred model performs better than the random walk model both in the in-sample and out-of-sample forecasts. For instance, we find our estimates of RMSE and ARMSE to be relatively smaller for the augmented Phillips curve predictive model as against the random walk model.

\section{Conclusion and recommendation}

Using monthly time-series dataset of oil-exporting and oilimporting countries, the study carried out an analysis on the significance of supply-side oil price shocks in Phillips curve predictability of inflation. Essentially, it considered both the traditional demand-side Phillips curve and a multiple-factor, activity-based predictive regression using the ARDLframework. The study explored the rolling window approach to forecasting and considered multiple out-of-sample sub-periods that included $50 \%$ and $75 \%$ of the total observations. The study found that augmenting the traditional demand-side Phillips curve with supply-side oil price shocks matter for Phillips curve accuracy in the predictability of inflation. For robustness and consistency check, the study explored RMSE and its adjusted version, and the findings consistently revealed that supply-side oil price shocks are crucial for understanding inflation dynamics. In accounting for supply-side oil price shocks activity, the predictive model appears to be more accurate in forecasting inflation relative to the traditional demand-side Phillips curve as well as the famous random walk approach to forecasting inflation. Thus, the study recommends that the quest to constantly produce accurate inflation forecast by monetary policy authorities in oil-importing and the oilexporting countries can be attained by expanding the tools for forecasting inflation to include international oil prices, reflecting the supply-side of inflation in these economies. Essentially, acknowledging the role of oil prices in the predictability of inflation by relevant authorities in the investigated oil-importing and oil-exporting economies will assist in the coordination of policies that are concerned about ensuring price stability.

\section{Acknowledgements}

The authors wish to express their deep appreciation to the African Economic Research Consortium (AERC) and the European Union Intra-African Academy, 2018, for their financial support to carry out this research. They are also grateful to AERC reviewers and resource persons for their comments and suggestions that helped shape the ideas presented in this study, consequently improving the overall quality of the article. However, the findings made and opinions expressed in this article are exclusively those of the authors who are also solely responsible for the content and any errors.

\section{Competing interests}

The authors have declared that no competing interest exists.

\section{Authors' contributions}

O.J.A. conceptualised and designed the study, acquired data, performed the statistical analysis and drafted the manuscript. He contributed almost $85 \%$ of the study. H.N. participated in the design of the study, interpretation of the results and the writing of the article. He contributed $15 \%$ of the study.

\section{Ethical consideration}

Ethical approval to conduct the study was obtained from the University of KwaZulu-Natal (Ref No. HSS/0928/018D) on 12 July 2018.

\section{Funding information}

This research received a financial grant from African Economic Research Consortium (AERC), Nairobi, Kenya (Ref No.: TT17018).

\section{Data availability statement}

Data are available and accessible for sharing or upload upon reasonable request to the author.

\section{Disclaimer}

The views and opinions expressed in this article are those of the authors and do not necessarily reflect the position of any affiliated agency of the authors.

\section{References}

Ang, A., Bekaert, G. \& Wei, M., 2007, 'Do macro variables, asset markets, or surveys forecast inflation better?', Journal of Monetary Economics 54, 1163-1212. https:// doi.org/10.1016/j.jmoneco.2006.04.006

Ascari, G., 2000, 'Optimising agents, staggered wages and persistence in the rea effects of money shocks', The Economic Journal 110, 664-686.

Atkeson, A. \& Ohanian, L., 2001, 'Are Phillips curves useful for forecasting inflation?', Federal Reserve Bank of Minneapolis Quarterly Review 25(1), 2-11. https://doi. org/10.21034/qr.2511

Banbura, M. \& Mirza, H., 2013, 'Forecasting Euro area inflation with the Phillips curve', Mimeo. [Google Scholar].

Brayton, F., Roberts, J.M. \& Williams, J.C., 1999, What's happened to the Phillips curve?, Federal Reserve Board, FEDS Paper No. 49, viewed n.d., from http://www. federalreserve.gov/pubs/feds/1999/199949/199949/12.05.2018/53abs.html.

Canova, F., 2007, 'G7 inflation forecasts: Random walk, Phillips curve, or what else?', Macroeconomic Dynamics 11, 1-30. https://doi.org/10.1017/S136510 $050705033 \mathrm{X}$

Cecchetti, S.G., 1995, 'Inflation indicators and inflation policy', in B.S. Bernanke \& J.J. Rotemberg (eds.), NBER macroeconomics annual 1995, vol. 10, pp. 189-219, The MIT Press, Cambridge, MA

Cecchetti, S.G., Rita, S.C. \& Charles, S., 2000, 'The unreliability of inflation indicators', Federal Reserve Bank of New York Current Issues in Economics and Finance 6(4), 1-6.

Chen, Y., Turnovsky, J.S. \& Zivot, E., 2014, 'Forecasting inflating using commodity price aggregates', Journal of Econometrics 185, 117-134.

Coibion, O. \& Gorodnichencko, Y., 2015, 'Is the Phillips curve alive and well after all? Inflation expectation and the missing disinflation', American Economic Journal: Macroeconomics 7(1), 197-232. https://doi.org/10.1257/mac.20130306 
Diron, M. \& Mojon, B., 2008, Are inflation targets good inflation forecasts? Economic perspectives, pp. 33-45, Federal Reserve Bank of Chicago, Chicago, IL.

Dotsey, M. \& Stark, T., 2005, 'The relation between capacity utilization and inflation', Federal Reserve Bank of Philadelphia Business Review Q2, 8-17.

Gordon, R.J., 1982, 'Inflation, flexible exchange rates, and the natural rate of unemployment', in M.N. Baily (ed.), Workers, jobs and inflation, pp. 89-158, The Brookings Insitution, Washington, DC.

Jaditz, T. \& Sayers, S., 1994, Predicting inflation, Manuscript, Bureau of Labor Statistics, India.

Matheson, T., 2006, Phillips curve forecasting in a small open economy, Reserve Bank of New Zealand Discussion Papers, NO. 2006:01.

Moosa, I.A. \& Burns, K., 2012, 'Can exchange rate models outperform the random walk? Magnitude, direction, and profitability as criteria', Economia Internazionale 65, 473-490.

Narayan, P.K. \& Gupta, R., 2015, 'Has oil price predicted stock returns for over a century?', Energy Economics 48, 18-23. https://doi.org/10.1016/j.eneco.2014.11.018

Narayan, P.K., Liu, R. \& Westerlund, J., 2015, 'A GARCH model for testing marke efficiency', Journal of International Financial Markets Institutions and Money 41(March), 121-138. https://doi.org/10.1016/j.intfin.2015.12.008

Orphanides, A. \& Van Norden, S., 2004, 'The reliability of inflation forecasts based on output gap estimates in real-time', Journal of Money, Credit and Banking 37(3), 583-600.. https://doi.org/10.1353/mcb.2005.0033

Pesaran, M., Shin, Y. \& Smith, R., 2001, 'Bounds testing approaches to the analysis of the level relationship', Journal of Applied Econometrics 16, 289-326. https://doi. org/10.1002/jae.616

Rapach, D.E., Strauss, J.K. \& Zhou, G., 2010, 'Out-of-sample equity premium prediction: Combination forecasts and links to the real economy', Review of Financial Studies 23, 821-862. https://doi.org/10.1093/rfs/hhp063

Salisu, A.A., Ademuyiwa, I. \& Isah, K.O., 2018, 'Revisiting the forecasting accuracy of the Phillips curve: The role of oil price', Energy Economics 70(February), 334-356. https://doi.org/10.1016/j.eneco.2018.01.018
Salisu, A.A. \& Fasanya, I.O., 2013, 'Modelling oil price volatility with structural breaks', Energy Policy 52, 554-562. https://doi.org/10.1016/j.enpol. 2012.10.003

Salisu, A.A. \& Isah, K.O., 2018, 'Predicting US inflation: Evidence from a new approach', Economic Modelling. https://doi.org/10.1016/j.econmod.2017.12.008

Salisu, A.A., Isah, O.K., Oyewole, J.O. \& Akanni, O.L., 2017, 'Modelling oil priceinflation nexus: The role of asymmetries', Energy 125, 97-106. https://doi. org/10.1016/j.energy.2017.02.128

Stock, J.H. \& Watson, M.W., 1996, 'Evidence on structural instability in macroeconomic time series relations', Journal of Business and Economic Statistics 14(1), 11-30. https://doi.org/10.1080/07350015.1996.10524626

Stock, J.H. \& Watson, M.W., 1999, 'Forecasting inflation', Journal of Monetary Economics 44, 293-335. https://doi.org/10.1016/S0304-3932(99)00027-6

Stock, J.H. \& Watson, M.W., 2003, 'Forecasting output and inflation: The role of asset prices', Journal of Economic Literature 41, 788-829. https://doi.org/10.1257/jel.41.3.788

Stock, J.H. \& Watson, M.W., 2007, 'Why has U.S. inflation become harder to forecast?', Journal of Money, Credit, and Banking 39, 3-34. https://doi.org/10.1111/j.1538 4616.2007.00014.x

Stock, J.H. \& Watson, M.W., 2008, Phillips curve inflation forecast, NBER Working Paper 14322 The MIT Press, Cambridge, MA.

Stock, J. \& Watson, M., 2009, 'The Phillips curve inflation forecasts in understanding inflation and the implications for monetary policy: A Phillips curve retrospective', in Proceedings of the Federal Reserve Bank of Boston's Annual Economic Conference, MIT Press, Cambridge, MA

Stockton, D.J. \& Glassman, J.E., 1987, 'An evaluation of the forecast performance of alternative models of inflation', The Review of Economics and Statistic 69, 108117. https://doi.org/10.2307/1937907

Welch, I. \& Goyal, A., 2008, 'A comprehensive look at the empirical performance of equity premium prediction', The Review of Financial Studies 21(4), 1455-1508. https://doi.org/10.1093/rfs/hhm014 